\title{
Hemangiossarcoma metastático em bovino
}

Gabriela Oliveira Pereira, Nathalia da Silva Carvalho, Paula Dias Retamero, Mariana Correia Oliveira, Daniel Guimarães Ubiali“

Setor de Anatomia Patológica, Departamento de Epidemiologia e Saúde Pública, Universidade Federal Rural do Rio de Janeiro (UFRRJ), Seropédica, RJ, Brasil

*Autor correspondente

e-mail: danielubiali@hotmail.com

\section{Resumo}

O hemangiossarcoma é uma neoplasia mesenquimal maligna de células endoteliais, que acomete principalmente cães, mas também equinos, bovinos, caprinos, suínos e ovinos. Essa neoplasia pode ser primária de qualquer tecido, contudo origina-se mais frequentemente no baço, coração, pele e fígado. As metástases têm maior ocorrência nos pulmões. Em ruminantes, todavia, existem poucos registros de Hemangiossarcoma. Descreve-se o caso de uma vaca, da raça Girolando, com 10 anos de idade, proveniente do município de Vassouras-RJ, que apresentou hemoptise bilateral. Ainda se observou perda de apetite, febre, emagrecimento, diminuição severa da produção leiteira (queda de 28 litros) e sibilos respiratórios contínuos observados durante a auscultação torácica. Realizou-se tratamento com Florfenicol e Dexametasona; houve melhora transitória e após cinco dias de evolução clínica a vaca morreu. Realizouse necropsia e coleta de fragmentos de fígado, baço, pulmões, encéfalo, rins, coração, intestino grosso, linfonodos mediastínico e mesentérico, que foram fixados em formalina a 10\% tamponada e processados para histopatologia. Macroscopicamente observaram-se pulmões com grandes áreas hemorrágicas, mais evidentes na porção ventral dos lobos pulmonares. No fígado havia áreas multifocais deprimidas e escuras (teleangiectasia). No baço havia uma massa com 10x8x5cm, macia e vermelha. No exame microscópico do pulmão, fígado e baço observam-se extensas áreas hemorrágicas separando o parênquima normal do órgão; nessas áreas há proliferação de células endoteliais neoplásicas fusiformes com moderado pleomorfismo. As células neoplásicas estão arranjadas em pequenos grupos em meio à hemorragia ou em fitas, e sustentadas por um estroma colagenoso. Os núcleos são pleomórficos e variam de fusiformes, ovoides ou esféricos, e por vezes hipercromáticos ou vesiculares e com nucléolos evidentes. As figuras de mitoses são 
frequentes. Observa-se grande quantidade de siderófagos e edema. Interpretou-se que o sítio primário da neoplasia localizava-se no baço e com metástase para pulmão e fígado. Em um levantamento de lesões em abatedouros de bovinos no Canadá, o hemangiossarcoma representou 0,3\% (4/1370). No Brasil, em um estudo realizado no laboratório de Patologia Veterinária da Universidade Federal de Santa Maria, apenas um caso de hemangiossarcoma foi diagnosticado em um total de 65 neoplasias diagnosticadas nos abatedorosfrigoríficos do Rio Grande do Sul. Nas descrições histopatológicas de hemangiossarcoma em uma vaca descritas na Universidade da Pensilvânia, Estados Unidos, a arquitetura da neoplasia foi semelhante ao observado nesta vaca, e acometeu fígado e baço. As hemorragias pulmonares que causaram hemoptise devem ser diferenciadas de outras doenças que causam hemorragias, como a forma aguda da intoxicação por Pteridium arachnoideum, a intoxicação por derivados cumarínicos e a síndrome da veia cava caudal. Conclui-se que o hemangiossarcoma deve ser incluído nos diagnósticos diferenciais de doenças neoplásicas que afetam bovinos e que cursam com hemorragias. 